\title{
DE LA CONSTITUCIÓN Y LAS CONSTITUCIONES EN EGIPTO CONTEMPORÁNEO (2011-2014): ANÁLISIS Y REFLEXIONES INICIALES
}

\author{
JOSÉ CARLOS CASTAÑEDA REYES \\ Universidad Autónoma Metropolitana
}

A lo largo del proceso de insurrección popular iniciado en el país del Nilo en enero de 2011, tres textos constitucionales tuvieron vigencia; el último de ellos, promulgado en enero de 2014, corolario fundamental de las dos thaweratanni masriyyatâ$n i$, las dos "revoluciones egipcias" que se desarrollaron en ese periodo. Como uno de los resultados más importantes de la insurrección popular, este último texto refleja la ideología del movimiento y los objetivos a largo plazo que los insurrectos se propusieron alcanzar.

En el presente artículo, resumen de un trabajo más amplio sobre el tema, se resaltan las principales características del texto constitucional de 2014, que puede ser una base jurídica para lograr cumplir parte del programa de búsqueda de justicia social que el movimiento popular egipcio tuvo como una de sus metas fundamentales desde su inicio. Se hace también una breve referencia - por cuestiones editoriales de extensión- a los otros documentos de carácter constitucional que estuvieron vigentes en esta etapa crucial en la historia del Egipto contemporáneo: la Declaración Constitucional de 2011 y la Carta Magna de 2012.

Este artículo fue recibido por la dirección de la revista el 12 de septiembre de 2014 y aceptado para su publicación el 19 de enero de 2015. 


\section{Introducción}

Los días 14 y 15 de enero de 2014, apenas diez antes del tercer aniversario de la primera thawra masriya, el pueblo egipcio participó en un nuevo referéndum para aceptar o rechazar el texto constitucional preparado por la Comisión Revisora de la Constitución de 2012, nombrada luego de que el rechazo popular expulsara a Mursi del poder. Se trataba de uno de los puntos torales de la "hoja de ruta" que se estableció entonces para volver lo antes posible a la normalidad cotidiana en el país.

En efecto, este programa implicaba integrar un gobierno de coalición o de unidad nacional, un comité de reconciliación social y otro para enmendar la Constitución. El nuevo primer ministro debía enfocarse en resolver la problemática económica y preparar las elecciones legislativas y presidenciales bajo las bases de la nueva Constitución.

En relación con estas medidas, urgentes para lograr la reconciliación nacional que tanto requiere el país del Nilo, destacó la revisión del criticado texto constitucional impulsado por la Hermandad y que fue derogado tras la caída de Mursi. En efecto, se conformó un comité de diez juristas, revisores del texto, que concluyó su tarea en tiempo y forma y dio paso a la comisión de cincuenta personalidades, presidida por Amr Mousa, fundamentalmente liberales, pero con una participación de representantes del islamismo (cuatro entre cincuenta, uno del partido salafista y tres miembros de Al-Azhar, ${ }^{1}$ porcentaje correcto si se recuerda el número de los manifestantes en la primera fase del movimiento popular de 2011), quienes quedaron encargados de redactar la versión final de la nueva Constitución egipcia (en dos meses de trabajo forzado), la cual se sujetó entonces a plebiscito.

Parece inaceptable que, sin más, se considere que estos cincuenta pensadores y líderes sociales - intelectuales, artistas, profesores universitarios, líderes sindicales, políticos profesionales, jóvenes miembros de los grupos que condujeron las protestas contra Mubarak y Mursi, musulmanes y coptos- fueran marionetas que respondieron a las indicaciones del general Abdel

${ }^{1}$ Nada Hussein Rashwan, "Inside Egypt's Draft Constitution: Role of Sharia Redefined”, Al Abram Online, 12 de diciembre de 2013. 
Fattah Al-Sisi y del ejército, que supuestamente fue responsable del "golpe de Estado" contra Mursi. ${ }^{2}$ De hecho, los trabajos de la Comisión fueron públicos - y la prensa egipcia hizo un seguimiento puntual del proceso, que así pudo conocerse plenamente $-{ }^{3}$ e incorporaron los planteamientos de los miembros de la sociedad; por ejemplo, los periodistas y su sindicato aceptan que $90 \%$ de sus propuestas fueron integradas al texto constitucional. ${ }^{4} \mathrm{Y}$ la adopción de un principio fundamental, el de la tasa progresiva en el pago de impuestos, mecanismo importante de redistribución del ingreso, fue una proposición de uno de los “jóvenes revolucionarios”, Mohamed Wael Ghonim. ${ }^{5}$

Por lo tanto, parece que hay una verdadera posibilidad de encauzar las fuerzas del cambio en el país a partir del texto constitucional. Sin duda, el preámbulo del documento, que encierra los grandes objetivos del movimiento popular egipcio, es una declaración fundamental de los principios insurreccionales en los dos textos constitucionales, de 2012 y 2014. En general, el texto constitucional de 2014 recibió un apoyo total del sector islámico ligado con el salafismo, opuesto a la Hermandad $\mathrm{Mu}-$

${ }^{2}$ El papel y la consideración que el ejército tiene para millones de egipcios es un punto básico que no podemos discutir aquí. Baste recordar la opinión de Hoda Abdel-Nasser, hija de Gamal Abdel-Nasser, historiadora y politóloga de la Universidad de El Cairo y uno de los "Sabios" propuestos por los jóvenes que hicieron la primera "revolución” en 2011 para dirigir al país luego del triunfo: el ejército debe ser visto como una fuerza-pivote, "Las fuerzas armadas egipcias estuvieron tradicionalmente del lado de las masas... Yo pienso que es seguro argumentar que el papel de las fuerzas armadas en el Egipto contemporáneo, en la presente revolución, tiene que ser determinado sobre esa base. El ejército, al igual que el resto del pueblo de este país, va a ir a través de una nueva fase de democratización". Gamal Nkrumah, "Nasser and Now", Al Abram Weekly, 14 de febrero de 2011.

${ }^{3}$ Como ejemplos, $c f$. Gamal Essam El-Din, "Charting the Future", Al Abram Weekly, 27 de noviembre de 2013, y Salma Shukrallah, "Egypt's Constitution: Who is backing It and Why?", Al Abram Online, 9 de enero de 2014. Ello permitió escuchar voces críticas de la marcha del proceso de revisión de la Carta Magna. Cf., por ejemplo, Sarah El Masry, "Constitutional Amendments: Repeating Past Mistakes?", Daily Neres Egypt, 4 de septiembre de 2013. Una gran enseñanza se advierte aquí: fue del conocimiento público la marcha de los trabajos del comité, al igual que los borradores iniciales propuestos del articulado, lo cual fue muy saludable para la creación de una "conciencia democrática" en Egipto.

${ }^{4}$ Ayat Al-Tawy, "Inside Egypt's Draft Constitution: Progress on Key Freedoms", Al Ahram Online, 12 de diciembre de 2013.

${ }^{5}$ El-Din, "Charting the Future", op. cit. El libro que recoge la experiencia de lucha de Wael Ghonim es Revolution 2.0. The Power of the People is Greater than the People in Power. A Memoir, Londres, Harper Collins, 2012. 
sulmana desde antes de la caída de Mursi, pero también de los sectores "liberales", representados por el Frente de Salvación Nacional, integrado por el Partido Democrático Social Egipcio, la Corriente Egipcia Popular Nasserista, el Partido Conferencia de Amr Moussa, el Partido de los Egipcios Libres, el Partido Wafd y el Partido Tagammu. Los integrantes del movimiento Tamarrod la apoyaron también.

A pesar de las críticas de algunos de estos institutos políticos a la carta constitucional —en lo referente al ejército o a las concesiones "necesarias" al sector islámico-, se consideró necesario apoyarla como un medio de volver a la "normalidad democrática" del país; en cambio, los artículos "promilicia” fueron la causa de que el Frente del Camino de la Revolución, el Movimiento 6 de Abril, el Partido de los Socialistas Revolucionarios y el Partido Egipto Fuerte rechazaran el texto. El Partido Constitución, de Mohamed El-Baradei, evitó pronunciarse sobre la nueva Constitución tras considerar la situación de persecución que han sufrido los miembros de la oposición, la represión contra los Hermanos, y los arrestos y los juicios contra los liberales con base en la reciente "ley antiprotesta". ${ }^{6}$

Empero, la perspectiva de los observadores externos fue más crítica: Democracy International, por ejemplo, una misión de observación internacional, señaló que el referéndum de 2014 quedó marcado por las presiones gubernamentales contra la oposición al texto constitucional; en general, se mantuvo una atmósfera inducida al voto por el "Si'”, y se presionó a los posibles disidentes. La presencia de las fuerzas de seguridad fue muy marcada, aun en los recintos para el voto, donde no hubo la secrecía necesaria. ${ }^{7}$ En cambio, para la misma Al-Jazeera, la votación en favor de la Constitución de 2014 fue abrumadora: $97 \%$ votaron por aceptar el documento en una participación de más de 17 millones de egipcios, 38\% del padrón oficial, lo cual le confirió un respaldo ligeramente mayor al que en su momento recibió la Constitución de 2012. ${ }^{8}$

\footnotetext{
${ }^{6}$ Shukrallah, "Egypt's Constitution: Who is backing It and Why?", op. cit.

${ }^{7}$ Drew Brammer, "Democracy International Expresses 'Serious Concerns' over Referendum”, Egypt Independent, 17 de enero de 2014.

${ }^{8}$ Corresponsales de Al Jazeera, "Egipcios dicen 'sí' a la nueva Constitución”, Inter Press Service, 16 de enero de 2014.
} 
En cambio, la IV Internacional Socialista consideró el referéndum como un fraude político de la "Junta militar apoyada por Estados Unidos", que tan sólo pretendía darle al "sangriento golpe miliar" del 3 de julio de 2013 una cubierta seudolegal. ${ }^{9}$

\section{Análisis comparativo de los tres textos constitucionales, 2011-2014}

Vista como un instrumento que Mursi y los Hermanos intentaron utilizar para consolidar su poder, el texto constitucional de $2012^{10}$ fue criticado duramente por la oposición liberal en su momento. Se le vio sobre todo como el medio utilizado por Mursi para arrogarse poderes superiores a los que tuvo Mubarak, con el objetivo de crear un Estado fundamentado en la religión y con la perspectiva y los intereses de la Hermandad Musulmana, visión inaceptable para el grueso de la población egipcia ${ }^{11}$ como los acontecimientos probaron. ${ }^{12}$

Debe recordarse que en el mismo periodo estuvo en vigor también la Declaración Constitucional de $2011,{ }^{13}$ que fue el instrumento jurídico que utilizó el Consejo Supremo de las Fuerzas Armadas durante su gobierno. Este texto fue también ratificado por un referéndum popular el 19 de marzo de $2011,{ }^{14} \mathrm{y}$ sustituyó, momentáneamente, la Constitución de 1971, reformada en 2007, base jurídica de la dictadura de Mubarak. ${ }^{15}$

${ }^{9}$ Alex Lantier, "Low Turnout as Egypt's US-Backed Junta Holds Constitutional Referendum”, World Socialist Web Site, 16 de enero de 2014.

${ }^{10} \mathrm{Vid}$. The Constituent Assembly, The New Constitution of the Arab Republic of Egypt. Approved on 30 November 2012, traducción extraoficial preparada por The International Institute for Democracy and Electoral Assistance.

${ }^{11}$ Galal Nassar, "The Battle over the Constitution", Al Abram Weekly, 2 de enero de 2013.

${ }^{12}$ Un análisis crítico del texto constitucional de 2012 en idem.

${ }^{13}$ Egyptian Government, "Constitutional Declaration 2011”, Egyptian Government Services Portal.

${ }^{14}$ Según recuerda Johannes Stern, "Egypt's New Constitution Legitimizes Coup, Enshrines Military Dictatorship”, World Socialist Web Site, 19 de diciembre de 2013.

${ }^{15}$ Este texto constitucional en Egyptian State, "The Constitution of the Arab Republic of Egypt" [1971, reformada en 1980], Egyptian State Information Service Website. Posteriormente, en el periodo 2005-2007, sufrió nuevas reformas que pueden leerse en Al Abram Weekly Online, "Constitutional Articles: Then and Now", 26 de marzo de 2007. Primera versión en inglés del texto constitucional redactado en 2013 
La Constitución de 2011 fue diseñada exclusivamente para el momento de transición, luego de la caída de Mubarak, para otorgar, en el artículo 54, un marco jurídico mínimo al Consejo Supremo de las Fuerzas Armadas. Es un texto pragmático que no propone un sistema político nuevo ni cambios mayores en la organización del gobierno. Tímidamente postulaba la búsqueda de la justicia social como un objetivo del gobierno (arts. 5 y 25). Se reconoce asimismo como un documento de transición, por lo que su artículo 60 prevé la conformación de una Asamblea Constituyente que redacte un nuevo texto constitucional. El artículo 2 es retomado de la Constitución egipcia anterior, y su redacción es igual en las Constituciones de 2012 y 2014. Quizá uno de los artículos más relevantes sea el 4, que prohíbe la conformación de partidos políticos con bases religiosas, premonición de lo que habría de suceder.

La Constitución de 2012 es, desde luego, mucho más rica. Su preámbulo nos parece más claro y contundente que el de la Constitución de 2014 en cuanto a la incorporación de los objetivos fundamentales de justicia social de la primera thawra. Ello lo convierte, empero, en el ejemplo más claro de la demagogia de la Hermandad Musulmana, que nunca se preocupó por respetar a aquellos que los externaron, casi mil egipcios que lucharon y murieron, la gran mayoría ajenos a la asociación de los Hermanos, pero con las mismas ideas tan brillantemente expresadas en ese preámbulo.

Independientemente del artículo 2, las preocupaciones religiosas de la Hermandad Musulmana se manifiestan en los artículos 44 y 219 , eliminados del texto constitucional de 2014. Al preservarse el artículo 2 se mantiene la posición de la sharía en la conciencia social egipcia, pero se previene cualquier violación de las otras disposiciones constitucionales, según opina Adel Ramadan, asesor legal de la organización no gubernamental Iniciativa Egipcia para los Derechos Personales; a ello se aúna la eliminación del artículo 219. Por lo demás, el contenido del ar-

\footnotetext{
y aprobado en el referéndum de 2014 en The Cairo Post, "2014 Constitution”, 7 de diciembre de 2013. No hay grandes diferencias con la versión aparecida posteriormente, todavía "extraoficial”, publicada por el mismo gobierno egipcio en Egyptian State, "Constitution of the Arab Republic of Egypt 2014", Egyptian State Information Service Website.
} 
tículo 2 ya había sido sancionado jurídicamente desde 1985 por la Corte Constitucional Suprema, formaba parte de la Constitución de 1971 y en sí mismo no era una novedad. En cambio, la problemática derivaba de los artículos 7 y 219 de la Constitución de 2012. ${ }^{16}$

Por otro lado, el contenido de la Constitución de 2012 es positivo en muchos de sus artículos, que fueron retomados y enriquecidos en la redacción de la Constitución de 2014. Queda abierto a la discusión por qué se eliminó el artículo 232, que sancionaba ejemplarmente a los miembros del Partido Nacional Democrático, corresponsable junto con Mubarak de la situación del país antes de enero de 2011. Se habló de que era ilegal y anticonstitucional segregar a los miembros del extinto Partido Nacional Democrático, como se hizo con ese artículo. ¿Pretexto para abrir una vía para su reincorporación a la vida política egipcia? ¿Ejemplo del "gatopardismo" en el régimen egipcio actual? El tiempo lo dirá, sobre todo cuando se establezca el primer parlamento del país. Lo que puede decirse por ahora es que los ex miembros del Partido Nacional Democrático apoyaron masivamente la elección de Al-Sisi, ${ }^{17}$ encabezados por el mismo Mubarak, quien pidió el voto para el general desde su lecho en el hospital militar de Maadi, donde se encuentra detenido. ${ }^{18}$

En cuanto a la Constitución de 2014, debe resaltarse el contenido de dos artículos poco mencionados, que parecen de gran relevancia: el artículo 227, que consagra el carácter "cohesivo" del texto constitucional y de sus partes, lo que puede ser la base para impedir reformas abruptas del documento, el cual debe mantener su unidad y principios originales sin caer en el inmovilismo.

$\mathrm{Al}$ respecto, el otro artículo es un buen ejemplo de lo anterior: el artículo 226 busca impedir una reforma abusiva de la Constitución en favor de aquel que intente perpetuarse en el poder, como ocurrió en el pasado. La única reforma válida al res-

\footnotetext{
${ }^{16}$ Rashwan, "Inside Egypt's Draft Constitution: Role of Sharia Redefined", op. cit.

${ }^{17}$ Gamal Essam El-Din, "A Tumultuous Year”, Al Abram Weekly, 2 de julio de 2014.

${ }^{18}$ Según comenta Lantier ("Low Turnout as Egypt's US-Backed Junta Holds Constitutional Referendum”, op. cit.), el ejemplo más claro del carácter reaccionario del referéndum por la Constitución de 2014.
} 
pecto debe consolidar el principio establecido por los legisladores: la no reelección presidencial por más de un periodo. De lo contrario, se iría en contra del espíritu plasmado en la redacción original del texto, y no se cumpliría el precepto constitucional de que una posible enmienda debe fortalecer ese principio primigenio, no violarlo en favor de intereses individuales o de grupo. Y como el artículo 227 consagra la idea de la cohesión necesaria de la Constitución de 2014, tal posible reforma sería una violación triple al principio original básico establecido por los legisladores, y más si se considera el artículo 5, que consagra el balance de poderes como un principio fundador de la nueva estructura política, resultado de las dos "revoluciones".

Además de estos dos artículos de gran importancia, el gran objetivo de la búsqueda de la justicia social permea el texto en diversos apartados, como el 8, los 17 a 21 y el 23 (establece gastos porcentuales mínimos del producto nacional bruto para salud pública de 3\%; educación básica, $4 \%$; educación superior, $2 \%$, e investigación científica, 1\%), o el 27 (el sistema económico debe favorecer la justicia social, no el enriquecimiento egoísta de unos cuantos). Empero, en el caso de la salud pública, algunas voces critican el texto como vago e insuficiente si se considera la Declaración de Abuya, Nigeria, de abril de 2011, donde los países de la Unión Africana señalaron que dicho gasto debía ser de un mínimo de $15 \%$ del presupuesto gubernamental. ${ }^{19}$

En esta perspectiva destaca también el artículo 38, que establece los impuestos progresivos como un medio para lograr la justicia social, planteamiento que ha sido ya puesto en práctica recientemente. ${ }^{20} \mathrm{Al}$ respecto, el abogado y activista

${ }^{19}$ Según el doctor Taher Mokhtar, miembro del Sindicato de Médicos Alejandrinos, entre otras críticas al texto constitucional. Randa Ali, "Inside Egypt's Draft Constitution: Questions over Social Justice”, Al Abram Online, 13 de diciembre de 2013.

${ }^{20}$ Hany Kadry, el nuevo ministro de Finanzas, anunció recientemente (marzo de 2014) algunas de estas disposiciones, que deberán profundizarse en el futuro: un impuesto temporal de $5 \%$ a personas cuyo ingreso anual exceda el millón de libras egipcias; además, el impuesto sobre la renta que estos mismos causantes pagarán será de $30 \%$. Actualmente, ingresos superiores a 250000 libras egipcias por año pagan $25 \%$ de impuesto. Además, se planea revisar el impuesto predial, quizá introducir el IVA, aumentar el impuesto a las importaciones y, seguramente, cobrar impuesto a las transacciones en la Bolsa de Valores. Sherine Abdel-Razek, "Hard Tax Choices", Al Abram Weekly, 20 de marzo de 2014. También se establecieron impuestos a artículos de lujo, como los cigarros y las bebidas alcohólicas, sobre todo los importados. Vid. 
Ibrahim Salamoni expresó: “¿Cómo puede haber justicia social si alguien que gana un millón de libras egipcias paga la misma tasa impositiva que el que gana 5000 ?”. ${ }^{21}$

Otros artículos, como el 78 (sobre la vivienda digna) o el 79 (sobre la alimentación adecuada y la autosuficiencia alimentaria), se enfocan también en el mismo problema.

La Constitución de 2014 plantea, por lo tanto, una serie de obligaciones sociales para el Estado que son una aguda carga presupuestal e implican la necesaria reforma del sistema económico para permitir un reparto más justo de la riqueza. En efecto, la búsqueda de la justicia social campea en los artículos constitucionales que se refieren al apoyo al campo, a la industria, al pueblo (artículos 27 a 46). No en balde la queja de Essam Refaat, antiguo editor en jefe de Al-Ahram Al-Iqtisadi: "En un momento en que el Estado está abandonando costosos subsidios y moviéndose en el camino de la privatización, esta Constitución [de 2014] obliga al gobierno a dedicar tremendas sumas de dinero para subsidiar la educación, la salud, y los servicios agrícolas". De ahí la crítica a la "ideología nasserista" que la Constitución refleja, según algunos. ${ }^{22}$

También se han escuchado críticas respecto de esta sección de la Constitución de 2014. Por ejemplo, Tamer Waguih, investigador de izquierda y miembro del Frente Camino de la Revolución, criticó la posible evasión de impuestos que la Constitución no prevé y la falta de control sobre los monopolios, que pueden igualmente afectar la economía del país. Lo más importante, el artículo 124 establece que el Estado está obligado a financiar con seguridad presupuestal no deficitaria cualquier gasto social, lo cual puede abrir el camino a las "medidas de

Osman El-Sharnoubi, "How Your Daily Life may change under El-Sisi”, Al Ahram Online, 25 de julio de 2014. El incremento del salario mínimo en un país es una medida fundamental, recomendada por la Comisión Económica para América Latina (Cepal) como uno de los mecanismos básicos "para avanzar en equidad y distribución del ingreso", y una política fiscal redistributiva, que "es el instrumento por excelencia que tiene un país para avanzar en la redistribución del ingreso". Declaraciones de Alicia Bárcena, secretaria ejecutiva de la Cepal. Véase Rafael Croda, "Lo importante es combatir la desigualdad", Proceso, año 37, núm. 1958, 11 de mayo de 2014, pp. 8-9. Cf. Orlando Delgado Selley, "Reducir la desigualdad extrema: una propuesta precisa", La Jornada, jueves 22 de mayo de 2014, sección Economía, p. 28.

${ }^{21}$ Ali, “Inside Egypt's Draft Constitution: Questions over Social Justice”, op. cit. ${ }^{22}$ Idem. 
austeridad" de que tanto gusta el capitalismo neoliberal, con lo cual es posible que se mantengan los mecanismos que provocan la pobreza del pueblo. ${ }^{23}$

Además del sistema político semiparlamentario ${ }^{24}$ o semipresidencialista del tipo "francés", ${ }^{25}$ los legisladores procuraron limitar el poder presidencial a través del contrapeso supervisor del recién creado parlamento, de no menos de 450 miembros (artículo 102), lo cual fue una decisión cuya funcionalidad deberá constatarse en la práctica cotidiana. En las primeras elecciones parlamentarias (pospuestas repetidamente y finalmente programadas para celebrarse entre el 21 de marzo y el 7 de mayo de 2015) ${ }^{26}$ se asignarían los asientos del Congreso a 120 candidatos de partidos, es decir, 20\%; 420 asientos a candidatos independientes, o sea 75\%, y 57 asientos a partir de un nombramiento presidencial, esto es $5 \%$, acorde a la nueva Constitución, pero en medio de la protesta de los partidos políticos y la suspicacia de muchos electores.

Sobre todo en el caso del sistema político debe esperarse la marcha de los acontecimientos para saber si efectivamente se tendrá un sistema que logre controlar las aspiraciones presidencialistas con un adecuado equilibrio de poderes. La aplicación del artículo 161 (la deposición del presidente de la República) deberá ser un arma que el nuevo parlamento esgrima, si es necesario, en el futuro. En cambio, el parlamento no puede ser disuelto por el presidente, $y$ menos durante un estado de

${ }^{23}$ Idem.

${ }^{24}$ ¿Por qué no se estableció un sistema parlamentario, como se propuso a la caída de Mubarak? Cf. José Carlos Castañeda Reyes, "El movimiento popular en Egipto en 2011: resultados primeros y tareas futuras", en Luis Mesa Delmonte (coord.), El pueblo quiere que caiga el régimen. Protestas sociales y conflictos en África del Norte y en Medio Oriente, México, El Colegio de México, 2012, pp. 244-245. Para Ahmed Khairy, dirigente del partido Egipcios Libres, tal sistema requiere la existencia de partidos políticos fuertes, que sencillamente no existen todavía en Egipto. De ahí el sistema que se adoptó, semipresidencialista más que semiparlamentario, en su opinión, útil en un periodo de transición política muy difícil, de 8 a 10 años. Véase Zeinab El Gundy, "Inside Egypt's Draft Constitution: Checks and Balances Mediate Presidential Power", Al Abram Online, 12 de diciembre de 2013.

${ }^{25}$ El-Din, "Charting the Future", op. cit. En este trabajo el autor comenta el proceso de redacción de artículos clave de la nueva Constitución. La redacción definitiva le dio la razón en muchas de sus apreciaciones.

${ }^{26}$ Gamal Essam El-Din, "Prepping the Poll", Al Abram Weekly, 15 de enero de 2015. 
emergencia (artículo 154). Por el contrario, la Constitución de 2012 permitía al presidente (léase Mursi) gobernar basado en decretos con fuerza de ley, en caso de la ausencia de las dos cámaras legislativas (artículo 129). Elshobaki considera que la división de poderes entre un presidente, un primer ministro y un parlamento electos impedirá monopolizar el poder, como lo hizo Mubarak; y agrega: "Al-Sisi conoce los riesgos para él si ignora la nueva Constitución y se convierte en un faraón”. ${ }^{27}$

Rizk y El-Sharnoubi ${ }^{28}$ destacan que otra diferencia importante entre las Constituciones estriba en el artículo 189 de la de 2014: el nombramiento del abogado general, cabeza del Ministerio Público de la nación, que es nombrado por el Consejo Judicial Supremo y no por el presidente de la República, como en el primer caso.

Cabe mencionar las dudas sobre el papel y las atribuciones del poder judicial en la Constitución de 2014, que se explican en los artículos 184, 186, 189, 191 y 192, fundamentalmente. Para Karim El-Chazly, ${ }^{29}$ es excesivo el carácter que ahí se confiere al poder judicial, que aparece sin cortapisas ni controles, completamente independiente y como un suprapoder con sus propias reglas y mecanismos internos, donde únicamente la "buena fe" de sus miembros es la garantía de su accionar frente a la nación. Para el autor, ello es absolutamente inaceptable para un adecuado y democrático equilibrio de poderes en el Egipto de 2014. Tal situación se explica por el papel del poder judicial en la historia reciente del país, ${ }^{30}$ pero evidentemente es motivo de reflexión. 2014.

${ }^{27}$ Gamal Essam El-Din, “A New Realism”, Al Abram Weekly, 29 de enero de

${ }^{28}$ Mariam Rizk y Osman El Sharnoubi, "Egypt’s Constitution 2013 vs. 2012: A Comparison”, Al Ahram Online, 12 de diciembre de 2013.

${ }^{29}$ Karim El-Chazly, "The Judiciary in the Constitution: Lost Opportunities on Reform and Enshrinement of the Judiciaries Impenetrability", Daily Neres Egypt, 22 de septiembre de 2013.

${ }^{30}$ Las acciones del poder judicial egipcio intentaron ser otro mecanismo para evitar los abusos de la Hermandad Musulmana durante el gobierno de Mursi. Dos medidas al respecto fueron claves: el 9 de marzo de 2013, la Corte Administrativa de El Cairo decidió suspender las elecciones parlamentarias programadas para empezar el 22 de abril de ese año. La Corte acusó a Mursi de violar el artículo 141 de la nueva Constitución al convocar unilateralmente a las elecciones, como lo hizo por decreto del 21 de febrero de 2013. Además, también violó el artículo 177, que establecía que la Suprema Corte Constitucional debía examinar las disposiciones legales políticas antes de que fuesen ratificadas por el presidente. Y, segundo, todavía de mayor relevancia: la 
Dentro del sistema político también es clave la lucha contra la corrupción, que afectó de manera tan grave al país durante el gobierno de Mubarak. Tal aspecto se retoma de manera explícita en el artículo 218.

Contrario a nuestra opinión, Samer Atala, profesor de la American University in Cairo, ${ }^{31}$ no encuentra un verdadero cambio en el sistema político que la Constitución de 2014 establece. Para él, el presidente sigue teniendo el poder de nombrar a los principales ministros, a $5 \%$ de los miembros del poder legislativo y, en suma, es "un intento de volver a embalar la antigua realidad" del país.

Otro tema controvertido es el papel que se le asigna al ejército en la estructura política del país sobre la base de su supuesta "independencia" de otros poderes en el artículo 234 transitorio, que durante los dos primeros periodos presidenciales exige la aprobación del nombramiento del ministro de Defensa por el Consejo Supremo de las Fuerzas Armadas. Además, el artículo 204 plantea la posibilidad de juzgar a civiles en tribunales militares, dependiendo del carácter del delito que se les impute. Debe decirse que en la Constitución de 2012, el artículo 198 presentaba una disposición similar, pero era ambigua en cuanto a los delitos que debían ser juzgados, los que ahora se precisan.

Según Sherif Tarek, ${ }^{32}$ se trata de un avance si se considera la falta de claridad al respecto de las Constituciones de 1971 y

\footnotetext{
Suprema Corte Constitucional, el 2 de junio del mismo año estableció que las leyes que regularon la Asamblea Consultiva o Shura Council, única en funcionamiento en ese momento, al igual que la Asamblea Constituyente que redactó la nueva Constitución, eran inválidas. Con ello se minó notablemente el carácter legal de la presidencia de Mursi y de la legislatura dominada por la Hermandad, y se arrojó la sombra de la ilegalidad sobre las disposiciones y leyes de la Asamblea. En cuanto al Constituyente, se reforzaba la idea de que la nueva Constitución no reflejó las perspectivas de la mayoría del pueblo, sino que quedó sesgada hacia la perspectiva fundamentalista de la Hermandad Musulmana. Así se debilitó seriamente la legitimidad del gobierno de Mursi, según el politólogo de la American University in Cairo, Emad Shahin. Esta acción legal y jurídica, junto con la participación popular, fueron claves para la crisis definitiva del gobierno de la Hermandad Musulmana. José Carlos Castañeda Reyes, “'El islam [no ha sido] la solución'. Egipto bajo el gobierno de los Hermanos Musulmanes (2012-2013)”, Estudios de Asia y Africa, vol. XLIX (2), núm. 154, mayo-agosto de 2014, pp. 537-538.

${ }^{31}$ Samer Atala, "Egypt's 'New' Constitution: Repeating Mistakes", Al-Jazeera, 14 de enero de 2014.

${ }^{32}$ Sherif Tarek, "Inside Egypt's Draft Constitution: Debates over Military Powers Continue", Al Ahram Online, 12 de diciembre de 2013.
} 
2012. En cambio, el mismo autor indica que por "zonas militares" puede entenderse también espacios propiedad del ejército, como gasolineras, salones de fiesta, áreas recreativas o teatros, lo cual amplía el riesgo para los civiles de ser considerados "candidatos" a ser juzgados por los tribunales militares. ${ }^{33}$ También recuerda que a lo largo de 2011 y 2012, antes de la presidencia de Mursi, el Consejo Supremo de las Fuerzas Armadas, que gobernó Egipto entonces, condenó a miles de civiles a ser juzgados por tribunales militares en ese difícil periodo. Según un estudio de la organización Human Rights Watch, tan sólo entre el 28 de enero y el 10 de septiembre de 2011 fueron juzgados 12000 civiles por tribunales militares. ${ }^{34}$

La primera disposición puede considerarse acorde a su carácter, o sea, como una medida temporal que no puede mantenerse más allá del plazo fijado. En un país con una tradición militar como la egipcia, parece ser un mecanismo necesario para llevar a la estabilización de la situación política y transitar paulatinamente hacia un pleno gobierno de carácter civil; de hecho, Al-Sisi renunció a su militancia en el ejército al asumir la candidatura a la presidencia. Al menos el "Preámbulo" de la Constitución de 2014 insiste en que el Estado egipcio debe ser una democracia moderna con un gobierno civil, ni militar ni con tintes religiosos. ${ }^{35}$ No parece que deba exigirse que Egipto, por ahora, tenga un ministro civil de las fuerzas armadas, lo cual no sucede en general en países con sistemas democráticos ya consolidados.

En cuanto a la segunda medida, si bien parece orientarse sobre todo en contra de los grupos "terroristas", a futuro puede ser una de las armas para reprimir movimientos de oposición política o de protesta social, como lo ha sido hasta ahora. Ante ello debe ser objeto de una reforma constitucional necesaria, cuando el nuevo régimen político se consolide; modificación

${ }^{33}$ En un entrevista televisada, el general Medhat Radwan Ghazi, responsable de la Justicia Militar, señaló que una simple discusión con un empleado de una gasolinera propiedad del ejército llevaría al infractor a un juicio militar. Véase Al-Jazeera, "Comparing Egypt's 2012 and 2013 Constitutions”, 14 de enero de 2014.

${ }^{34}$ Stern, "Egypt's New Constitution Legitimizes Coup, Enshrines Military Dictatorship", op. cit.

35 Véanse los comentarios al respecto de Rizk y El Sharnoubi, "Egypt's Constitution 2013 vs. 2012: A Comparison”, op. cit. 
que no parece chocar con lo que dispone el artículo 237, también transitorio.

Otra es la perspectiva de Lantier, ${ }^{36}$ de la IV Internacional, quien considera el "carácter reaccionario" y contrarrevolucionario de la Constitución de 2014, sobre todo en este aspecto pues, según él, convierte al ejército en un Estado dentro del Estado y le confiere amplios poderes para suprimir a la oposición popular, más a la obrera, con base en los artículos 203, 204 y 234. En la misma línea, Johannes Stern ${ }^{37}$ considera que se busca tan sólo legitimar la dictadura militar a través del texto constitucional y defender el poder y los privilegios de los militares. Para él, el artículo 203 es fundamental, por permitir a los militares establecer el presupuesto de las fuerzas armadas e intervenir en asuntos de seguridad nacional, sin cortapisas. Con ello, se establece un instrumento jurídico para la represión del movimiento obrero y de la juventud egipcia; de hecho, mientras esta última mantenga su posición de rechazo al gobierno de Al-Sisi será muy difícil la reconciliación completa de los sectores sociales del país. ${ }^{38}$

Precisamente la falta de un verdadero consenso social que se reflejara en el texto constitucional es una de las principales debilidades que encuentra Atala ${ }^{39}$ en la Constitución de 2014, que, al igual que la de 2012, es un texto excluyente: o del sector liberal o del sector islámico, según el caso. Sin embargo, no parece ser así en la de 2014, pues hubo una representación del

${ }^{36}$ Lantier, "Low Turnout as Egypt's US-Backed Junta Holds Constitutional Referendum”, op. cit.

${ }^{37}$ Stern, "Egypt's New Constitution Legitimizes Coup, Enshrines Military Dictatorship”, op. cit.

${ }^{38}$ Para Mohamed Anwar Al-Sadat, presidente del partido liberal Reforma y Desarrollo, Al-Sisi debe conformar una base de apoyo amplia para su gobierno, en la que destaquen los jóvenes revolucionarios de 2011 y 2013, ahora afectados por la "ley antiprotestas" y que permanecen en la cárcel purgando severas penas, como es el caso emblemático de los fundadores del Movimiento 6 de Abril, el principal, Ahmed Maher, pero también Ahmed Doma y Mohamed Adel, entre otros. Bajo el cargo de tomar parte en una manifestación el 27 de noviembre de 2013, frente al Consejo de la Shura, el 22 de diciembre siguiente fueron condenados a tres años de prisión y a una multa de 100000 libras egipcias. Otros 100 activistas han sido sentenciados de manera similar con hasta dos años de cárcel por haber tomado parte en otra manifestación no autorizada el 25 de enero de 2014. Véase Khaled Dawoud, “A Positive Sign”, Al Ahram Weekly, 27 de marzo de 2014. Cf. El-Din, "A Tumultuous Year”, op. cit.

${ }^{39}$ Atala, "Egypt's 'New' Constitution: Repeating Mistakes”, op. cit. 
segundo sector en el comité redactor del texto, y concesiones concretas para que fuese aceptado por tal fracción, como finalmente ocurrió.

En suma, el papel y la fuerza del ejército egipcio son todavía muy importantes, y ello se refleja en el texto constitucional. Según Ahmed Fawzy, presidente del Partido Social Demócrata Egipcio, "los poderes de la milicia en la Constitución [de 2014] son abrumadores, y la hacen más poderosa que la autoridad ejecutiva". ${ }^{40}$ Por ello, Atala considera al ejército y las concesiones que la Constitución de 2014 le confiere el "principal obstáculo para transformar a Egipto en una verdadera democracia moderna". ${ }^{41}$ A una conclusión similar llega Ahmed Abd Rabou, quien igual considera que como nunca antes el sector militar egipcio adquiere plenos poderes para influir en la vida política del país $y$ defender sus intereses en los años por venir. Con la Constitución de 2014 se establece la tiranía de los militares sobre la ciudadanía, al conferirles absoluta independencia para suprimir cualquier movimiento de rebeldía y de oposición política. ${ }^{42}$

Finalmente, deben resaltarse otros artículos que, de cumplirse a cabalidad, podrían significar un importante cambio en algunos aspectos sociales fundamentales, y hasta en las costumbres tradicionales en Egipto. Resalta, desde luego, el artículo 11, muy claro en la defensa y la protección de la mujer, y muy superior al correspondiente de la Constitución de 2012 (artículo 10). En esta última prácticamente quedaba fuera la posibilidad de plantear al menos un cambio en la condición de la mujer fuera de su papel tradicional de madre de familia (de ahí la referencia a ella en cuanto base de la sociedad), posición que refleja la perspectiva de la Hermandad Musulmana, como comento en otro trabajo. ${ }^{43}$

${ }^{40}$ Tarek, “Inside Egypt's Draft Constitution: Debates over Military Powers Continue”, op. cit.

${ }^{41}$ Atala, "Egypt's 'New' Constitution: Repeating Mistakes”, op. cit.

${ }^{42}$ Ahmed Abd Rabou, "Civilian-Military Relations and the Position of Security Institutions in the 2014 Constitution", Daily Neres Egypt, 22 de septiembre de 2013.

${ }^{43}$ Cf. José Carlos Castañeda Reyes, "La segunda thawra masriya: de la responsabilidad histórica de los Hermanos Musulmanes a la 'Contrarrevolución' en Egipto contemporáneo”, ponencia presentada en el seminario Egipto: Situación Política Actual, 12 de mayo de 2014, Ciudad de México, Centro de Estudios de Asia y África de El Colegio de México, passim. 
El artículo 214 prevé la creación de dos consejos nacionales que pueden incidir en la condición femenina en Egipto, el de las Mujeres, y el de la Niñez y la Maternidad; un tema que deberá evaluarse con precisión en el futuro.

Otros artículos igualmente destacados son aquellos que regulan las relaciones laborales y los derechos de los trabajadores; entre ellos, la existencia de contratos colectivos y sindicatos que los defiendan (artículos 13 y 76); la regulación estatal de las relaciones entre capital y trabajo, y su apoyo a las medianas y pequeñas empresas productivas (artículo 28), con lo cual el Estado asume su necesario papel de regulador y garante de tales relaciones.

Contrario a esta perspectiva, los activistas egipcios ligados al sector laboral encuentran riesgos para el movimiento obrero futuro. Califican de "arbitraria" la idea de que las huelgas sean "reguladas por ley", ${ }^{44}$ pero de hecho no existe tal disposición, salvo que el artículo 15 se tome como tal. Para Fatma Ramadan, miembro directivo de la Federación Egipcia de Sindicatos Independientes, la Constitución de 2014 (artículo 76) es peor que la de 2012 (artículo 52) en cuanto a la defensa de los derechos laborales, pues favorece al sector patronal. ${ }^{45}$

También es necesario destacar que en la Constitución de 2014 se reconoce la importancia del ciberespacio y sus aplicaciones futuras en bien de la sociedad (artículo 31); la protección de los recursos naturales, al establecerse límites precisos para su explotación por los particulares (artículos 32, 45 y 46), y concretamente la preservación del río Nilo (artículo 44); la defensa y el fomento del patrimonio cultural egipcio en su carácter multicultural y multirreligioso (artículos 48-50); el impulso a la donación altruista de órganos (artículo 61); el apoyo a la libertad y la autonomía de las organizaciones no gubernamentales, sin cortapisas (artículo 75); la defensa y la protección de los derechos de los niños (artículo 80), de las personas discapacitadas (artículo 81), de los jóvenes y de los ancianos (artículos 82 y 83); el fomento al deporte (artículo 84); la salvaguarda de los op. cit.

${ }^{44}$ Al-Tawy, "Inside Egypt's Draft Constitution: Progress on Key Freedoms", ${ }^{45}$ Ibid., p. 3. 
derechos humanos y los tratados internacionales al respecto, que tendrán fuerza de ley en Egipto (artículo 93).

Finalmente, los artículos transitorios intentan resolver situaciones propias de los momentos de cambio e inquietud social que vivió el país desde la primera thawra. Además de lo comentado, el artículo 235 pretende compensar los ataques sufridos por la comunidad cristiana a manos de los extremistas de la Hermandad, al resaltar el carácter complementario que tiene la raíz copta para la cultura egipcia.

Por su parte, el artículo 236 aborda el problema de la aplicación de medidas de justicia social en las áreas más depauperadas del país (el Alto Egipto, Sinaí, Matrouh y Nubia), que requieren una atención inmediata. Destaca el plazo de 10 años para mejorar la situación en las regiones que se indican, con lo que se resalta la idea de la urgencia de llevar a cabo cambios concretos y rápidos, en la medida de lo posible. En la misma lógica se ubica el artículo 238, que propone alcanzar la reasignación de recursos presupuestales en salud pública, educación e investigación científica a más tardar en el año fiscal de 20162017, y no en un hipotético futuro de "felicidad dorada" que nunca llegue.

Finalmente, el artículo 241 deja abierta la posibilidad de revisar los episodios sangrientos que se presentaron durante los tres años más álgidos del movimiento popular, no únicamente para develar la "verdad histórica" tras ellos -importante pero que nada cambia-, sino además para asignar responsabilidades, tentativamente penales, a sus autores. Ello podría abrir el camino para una verdadera reconciliación nacional basada en la justicia y el castigo de los responsables y no en la impunidad y el olvido de las víctimas. ${ }^{46}$

La gran debilidad en relación con este contenido favorable a los grandes sectores sociales del país es que la Constitución de 2014 no parece incluir mecanismos para asegurar la aplicación de tales medidas. Es una de las grandes fallas del texto, que señala

${ }^{46}$ En cambio, Atala ("Egypt's 'New' Constitution: Repeating Mistakes”, op. cit.) considera este artículo como "extremadamente débil”, y sin asegurar garantías para que tal justicia se cumpla. Nuevamente, el autor no concede el beneficio de la duda al porvenir. 
Atala: ${ }^{47}$ ¿cómo asegurar su aplicación? En la mejor tradición egipcia, piensa el autor, lo que una mano concede la otra lo quita... Pero ello, según parece, es la aplicación práctica de un instrumento jurídico básico; deberá esperarse el resultado de la obra legislativa en los años por venir.

\section{Conclusión}

A pesar de la brevedad del análisis de los documentos, parece claro su carácter: la Declaración Constitucional de 2011 fue el instrumento pragmático utilizado por el sector militar egipcio para contener el impulso revolucionario popular; por su lado, la Carta Magna de 2012 fue empleada, vanamente, por los Hermanos Musulmanes para intentar consolidar su dominio de la vida política egipcia, lo que acabó en un fracaso gracias a la "segunda revolución". ${ }^{48}$

En cambio, parece que se sostiene nuestra propuesta inicial: como uno de los grandes resultados del movimiento popular iniciado en enero de 2011, surge el máximo instrumento jurídico de una nación moderna, que puede permitir construir paulatinamente una sociedad más justa y digna, que alcance la justicia social, lo que fue uno de los objetivos fundamentales de la insurrección del pueblo egipcio. Cada uno de los logros que recoge el texto constitucional de 2014 no fue una graciosa concesión de los sectores dominantes, sino una conquista popular que se alcanzó a partir de las grandes movilizaciones que el mundo atestiguara y que son ejemplo de lo que puede lograrse con la participación masiva del pueblo. Por lo tanto, la lucha por "el pan, la libertad, la justicia social y la dignidad humana" continuará y, de hecho, continúa en el país del Nilo.

Parece necesario recordar las reflexiones del profesor de ciencia política de la Universidad de El Cairo y analista político de Al-Abram, Amr Elshobaki, ${ }^{49}$ para quien la "revolución

${ }^{47}$ Idem.

${ }^{48}$ El estudio de la etapa de gobierno de la Hermandad en estos años lo realicé en “'El islam [no ha sido] la solución'...”, op. cit., passim.

${ }^{49}$ Amr Elshobaki, "Realidad y futuro de la Revolución egipcia”, Awraq, núm. 3, 2011, pp. 107-117, especialmente pp. 113-115. 
egipcia" tiene el gran valor, como ejemplo histórico, de mostrar un proceso revolucionario que, luego de haber logrado, sin violencia, la caída de un régimen corrupto e ineficaz, debía emprender el camino del saneamiento y la reforma de las instituciones, sin desmantelarlas de entrada, lo cual hubiera desembocado en una situación costosa y catastrófica, como la favorecida por los estadounidenses en Iraq luego de su intervención militar. En cambio, lo que seguía luego del rápido triunfo popular de 2011 era la reforma del Estado, "bajo la protección de una nueva Constitución y un nuevo marco jurídico" que diese certidumbre de que los restos del antiguo régimen no seguirían operando en detrimento de pueblo.

Elshobaki pensaba en la primera thawra. La labor de reforma de las instituciones estatales fue la tarea histórica que Mursi y la Hermandad Musulmana nunca realizaron, como analizo en otro trabajo, y su erróneo accionar tan sólo llevó a un segundo y aún más importante levantamiento popular. Lo que es más: el error de haber utilizado la Constitución (de 2012) para reforzar la concentración del poder, como intentó la Hermandad, jugó un claro papel de detonador de la nueva insurrección. ${ }^{50}$

Luego de la segunda thawra permanece la misma obra pendiente, bajo los mismos considerandos, que la nueva Constitución de 2014 debe permitir lograr, como instrumento jurídico indispensable para tal labor. Con ello se alcanzaría un digno corolario del sacrificio del pueblo egipcio durante sus dos "revoluciones".

El otro problema que debe discutirse es el papel del ejército en la insurrección popular. Además de lo dicho, debe recordarse la reflexión de Jean-Françoise Daguzan: ${ }^{51}$ luego de que en la década de 1960 el ejército egipcio fue percibido como la punta de lanza en la construcción de un Estado moderno, aparece actualmente como un "modelo conservador" cuya principal preocupación es asegurar la perennidad de los privilegios de los altos mandos, en tanto que en una posición más sensible y reactiva a las aspiraciones populares se encuentran los soldados

${ }^{50}$ Jean Messiha y Frédéric Teulon, "Egypte : de une révolution à une autre?", Maghreb-Machrek, núm. 216, otoño de 2013, p. 137.

${ }^{51}$ Jean-Françoise Daguzan, “Armées et société dans le Monde Arabe: entre révolte et conservatisme”, Maghreb-Machrek, núm. 214, invierno de 2012, p. 21. 
rasos. Lo que es más: este autor se pregunta: “¿Las revoluciones árabes no son más que engañifas que buscan restaurar el poder perdido de los ejércitos como el caso egipcio podría dejarnos suponer?... El Egipto de hoy podría, llegado el caso, corresponder a esta hipótesis". ${ }^{52}$

No es el momento de discutir esta perspectiva, que no acepto por dejar fuera la participación real, auténtica, en el proceso insurreccional del pueblo egipcio por mejorar sus difíciles condiciones de vida. Pero es necesario de todos modos consignarla, por las posibilidades de investigación y de reflexión que aporta.

Por ahora tan sólo queda recordar el comentario de uno de los jóvenes egipcios que celebraban la caída de Mursi: "Tal vez la historia no tenga lados. Tal vez sólo tenga momentos. Y cuando venga el momento de ver qué hacemos con los militares, pues... bueno, vendrá". ${ }^{53}$

Por lo tanto, ahora cabe seguir con atención la aplicación de los principios constitucionales. Ello es parte del análisis que, como escribía, debe realizarse dentro de un mínimo de cinco años a partir de la promulgación de la Constitución de 2014, para apreciar los resultados concretos del proceso insurreccional, del que la Carta Magna forma parte. Al menos en el campo de la protección de los derechos de la mujer (artículo 11), el sistema judicial egipcio parece decidido a evitar nuevos abusos: ${ }^{54} \mathrm{el}$ día 3 de junio de 2014, cuando Al-Sisi tomó posesión de su cargo y en medio de las celebraciones por su ascenso, en la misma plaza Tahrir, nueve hombres agredieron sexualmente a dos mujeres, madre e hija, lo que causó un gran impacto en la sociedad. Apresados y juzgados, siete de ellos fueron condenados a cadena perpetua, y los otros dos, a veinte años de cárcel..$^{55}$

52 "Les révolutions arabes ne sont-elles que des leurres visant à restaurer le pouvoir perdu des armées comme l'affaire égyptienne pourrait nous laisser supposer?... L'Égypte aujourd'hui pourrait le cas échéant correspondre à cette hypothèse...”. Ibid., p. 24.

${ }_{53}$ Declaración de Said Nashar (del movimiento Tamarrod) al periodista mexicano Témoris Grecko, "Egipto: el regreso de los generales”, Proceso, núm. 1914, 6 de julio de 2013, p. 56.

${ }^{54}$ Según un reporte de 2013 de la onU, 99.3\% de las egipcias se quejan de haber sufrido alguna forma de acoso sexual en su vida. Véase El-Sharnoubi, "How Your Daily Life may change under El-Sisi”, op. cit.

${ }^{55}$ Reem Leila, "Historic Ruling on Harassment", Al Abram Weekly, 24 de julio 
¿Será Egipto la punta de lanza para modificar el injusto sistema económico actual? Al menos la nueva Constitución reivindica el papel del Estado como garante de los intereses de las mayorías, no de unos cuantos privilegiados, y busca mecanismos para el mejor reparto de la riqueza, dentro del marco de un sistema económico capitalista atemperado por su acción. Exactamente lo contrario de lo que pregonan los organismos internacionales al servicio de los intereses del gran capital de nuestros días.

En el proceso de construcción de una sociedad más justa y digna, interrumpido abruptamente en la década de 1990, pero nunca cancelado como aspiración suprema de la Humanidad, destaca el ejemplo egipcio, y tanto los logros como los errores de los insurrectos del país del Nilo deberán ser analizados como parte del proceso revolucionario mundial. ${ }^{56}$

En tanto, la poderosa palabra de los sectores populares del Egipto de nuestros días se une a las voces del pasado que, en la misma tierra, mostraron desde hace milenios que el camino es la acción popular decidida y valiente, que antes y ahora busca construir una sociedad más justa y humana en beneficio del propio pueblo:

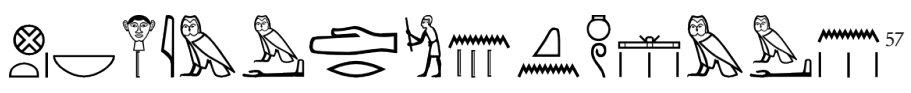

de 2014. Tal condena fue excepcionalmente severa. La nueva ley en la materia prevé castigos de seis meses en prisión y 3000 libras egipcias de multa al primo ofensor, y el doble de la pena al reincidente. Si el acosador tiene una posición de poder sobre la víctima -si es su jefe, su profesor-, la condena es mayor: una sentencia mínima de dos años de cárcel. Véase El-Sharnoubi, "How Your Daily Life may change under El-Sisi”, op. cit.

${ }^{56}$ De hecho, la IV Internacional Socialista ha resaltado, casi desde su inicio, la importancia del movimiento popular egipcio y sus implicaciones para la futura revolución socialista. Como ejemplo, $c f$. dos artículos de Johannes Stern, "The Way forward in Egypt", World Socialist Web Site, 26 de noviembre de 2012, y "Two Years of the Egyptian Revolution", World Socialist Web Site, 6 de febrero de 2013. Igual ha hecho Elshobaki, "Realidad y futuro de la Revolución egipcia", op. cit., p. 113, quien escribe: "la experiencia de la revolución egipcia se considera única, con un enorme potencial que ha superado a tantas otras experiencias del cambio en el mundo".

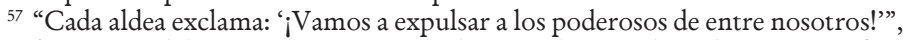
parágrafo 2,7-2,8 del papiro Ipuwer, en Alan Gardiner, The Admonitions of an Egyptian Sage from a Hieratic Papyrus in Leiden (pap. Leiden 344 recto), Leipzig, J. C. Hinrichs'sche Buchhandlung, 1909, p. 26. La traducción es mía, cotejada con la de diversos egiptólogos. La referencia a uno de los primeros movimientos populares de la 
Ésta es nuestra Constitución. El documento de la Revolución del 25 de enero, la Revolución que fue iniciada por nuestra juventud, la cual nuestro pueblo nutrió [...] Nosotros rechazamos, en la plaza Tahrir y a través del país, todas las formas de injusticia, opresión, tiranía, despotismo, exclusión, despojo, corrupción y monopolio. Nosotros públicamente demandamos, con la sangre de nuestros mártires, el dolor de nuestros heridos, los sueños de nuestros niños y la lucha de nuestros hombres y mujeres, nuestro absoluto derecho "[al] pan, [a la] libertad, [a la] justicia social y [a la] dignidad humana. ${ }^{58}$ Somos ciudadanos, mujeres y hombres; somos el pueblo egipcio, patronos en un Estado soberano; ésta es nuestra voluntad, y ésta, la Constitución de nuestra revolución. ${ }^{59}$

Dirección institucional del autor:

Departamento de Filosofía

Universidad Autónoma Metropolitana-Iztapalapa

Michoacán y La Purísima

Col. Vicentina, Iztapalapa

09340, México, D.F.

mrwti@xanum.uam.mx

t3myt75@gmail.com

\section{Bibliografía}

Aвd Rabou, Ahmed, "Civilian-Military Relations and the Position of Security Institutions in the 2014 Constitution", Daily News Egypt, 22 de septiembre de 2013. [www.dailynewsegypt. com/2013/09/22/minimum...unjust/, consultado el 18 de agosto de 2014.]

Abdel-RazeK, Sherine, "Hard Tax Choices”, Al Abram Weekly, 20 de marzo de 2014. [weekly.ahram.org.eg/News/5727/18/Hardtax...aspx, consultado el 20 de marzo de 2014.]

Al Abram Weekly Online, "Constitutional Articles: Then and Now", 26 de marzo de 2007. [weekly.ahram.org.eg/2007/837/eg13.htm, consultado el 26 de marzo de 2007.]

historia, acaecido precisamente en el Egipto antiguo, se encuentra en José Carlos Castañeda Reyes, Sociedad antigua y respuesta popular. Movimientos sociales en Egipto antiguo, México, Conacyt-UAm-Plaza y Valdés, 2003.

${ }_{58}$ The Constituent Assembly, The Nerw Constitution..., op. cit., "Preámbulo", p. 1. Parece, como dije, mucho más claro y directo este párrafo de la Constitución de 2012 que el similar de la de 2014.

59 The Cairo Post, "2014 Constitution”, op. cit. 
Al-Jazeera, “Comparing Egypt's 2012 and 2013 Constitutions”, 14 de enero de 2014. [www.aljazeera.com/news/middleeast/2014/01/ comparing-egypt-2012-2013-constitutions-20141144363151347. html, consultado el 14 de enero de 2014.]

Ali, Randa, "Inside Egypt's Draft Constitution: Questions over Social Justice", Al Ahram Online, 13 de diciembre de 2013. [english. ahram.org.eg/NewsContentPrint/1/0/88630/Egypt/0/-InsideEgypts-...aspx, consultado el 13 de diciembre de 2013.]

Atala, Samer, “Egypt's 'New' Constitution: Repeating Mistakes”, Al-jazeera, 14 de enero de 2014. [www.aljazeera.com/indepth/ features/2014/01/comparing-...htm, consultado el 14 de enero de 2014.]

Ayat Al-Tawy, "Inside Egypt's Draft Constitution: Progress on Key Freedoms", Al Ahram Online, 12 de diciembre de 2013. [english. ahram.org.eg/NewsContentPrint/1/0/88458/Egypt/0/-InsideEgypts-...aspx, consultado el 12 de diciembre de 2013.]

Brammer, Drew, "Democracy International Expresses 'Serious Concerns' over Referendum”, Egypt Independent, 17 de enero de 2014. [www.egyptindependent.com//print/2433616, consultado el 17 de enero de 2014.]

Castañeda ReYes, José Carlos, “El islam [no ha sido] la solución'. Egipto bajo el gobierno de los Hermanos Musulmanes (20122013)", Estudios de Asia y África, vol. XLIx (2), núm. 154, mayoagosto de 2014, pp. 509-551.

CASTAÑEDa ReYes, José Carlos, "El movimiento popular en Egipto en 2011: resultados primeros y tareas futuras", en Luis Mesa Delmonte (coord.), El pueblo quiere que caiga el régimen. Protestas sociales y conflictos en Africa del Norte y en Medio Oriente, México, El Colegio de México, 2012, pp. 231-252.

CASTAÑEDA ReYES, José Carlos, "La segunda thawra masriya: de la responsabilidad histórica de los Hermanos Musulmanes a la 'Contrarrevolución' en Egipto contemporáneo”, ponencia presentada en el seminario Egipto: Situación Política Actual, 12 de mayo de 2014, Ciudad de México, Centro de Estudios de Asia y África de El Colegio de México.

CASTAÑEDA ReYes, José Carlos, Sociedad antigua y respuesta popular. Movimientos sociales en Egipto antiguo, México, Conacyt-UAMPlaza y Valdés, 2003.

Corresponsales de Al Jazeera, "Egipcios dicen 'sí' a la nueva Constitución”, Inter Press Service, 16 de enero de 2014. [www.ipsnoticias. net/2014/01/egipcios-dicen-si-la-nueva-constitucion/, consultado el 16 de enero de 2014.] 
Croda, Rafael, "Lo importante es combatir la desigualdad", Proceso, año 37, núm. 1958, 11 de mayo de 2014, pp. 8-9.

Daguzan, Jean-Françoise, “Armées et société dans le Monde Arabe: entre révolte et conservatisme”, Maghreb-Machrek, núm. 214, invierno de 2012, pp. 9-30.

Dawoud, Khaled, “A Positive Sign”, Al Abram Weekly, 27 de marzo de 2014. [weekly.ahram.org/Print/5767.aspx, consultado el 27 de marzo de 2014.]

Delgado Selley, Orlando, "Reducir la desigualdad extrema: una propuesta precisa", La Jornada, jueves 22 de mayo de 2014, sección Economía, p. 28.

Egyptian Government, "Constitutional Declaration 2011”, Egyptian Government Services Portal. [www.egypt.gov.eg/english/laws/ constitution/, consultado el 28 de junio de 2013.]

Egyptian State, "Constitution of the Arab Republic of Egypt 2014", Egyptian State Information Service Website. [www.sis.gov.eg/ Newvr/Dustor-en001.pdf, consultado el 1 de agosto de 2014.] Egyptian State, "The Constitution of the Arab Republic of Egypt" [1971, reformada en 1980], Egyptian State Information Service Website. [www.sis.gov.eg, consultado el 7 de diciembre de 2013; y www.constitutionnet.org/files/Egypt\%20Constitution.pdf, consultado el 15 de julio de 2015.]

El-Chazly, Karim, "The Judiciary in the Constitution: Lost Opportunities on Reform and Enshrinement of the Judiciaries Impenetrability", Daily Neres Egypt, 22 de septiembre de 2013. [www.dailynewsegypt.com/2013/09/22/minimum...unjust/, consultado el 18 de agosto de 2014.]

El-Din, Gamal Essam, “A New Realism”, Al Ahram Weekly, 29 de enero de 2014. [weekly.ahram.org.eg/Print/5287.aspx, consultado el 29 de enero de 2014.]

EL-Din, Gamal Essam, “A Tumultuous Year”, Al Abram Weekly, 2 de julio de 2014. [weekly.ahram.org/print/6677.aspx, consultado el 2 de julio de 2014.]

EL-Din, Gamal Essam, "Charting the Future", Al Abram Weekly, 27 de noviembre de 2013. [weekly.ahram.org/print/4803.aspx, consultado el 27 de noviembre de 2013.]

EL-Din, Gamal Essam, "Prepping the Poll”, Al Abram Weekly, 15 de enero de 2015. [weekly.ahram.org/Print/10181.aspx, consultado el 15 de enero de 2015.]

El Gundy, Zeinab, “Inside Egypt's Draft Constitution: Checks and Balances Mediate Presidential Power", Al Abram Online, 12 de diciembre de 2013. [english.ahram.org.eg/NewsContent- 
Print/1/0/88274/Egypt/0/-Inside-Egypts-...aspx, consultado el 12 de diciembre de 2013.]

El Masry, Sarah, "Constitutional Amendments: Repeating Past Mistakes?”, Daily Neres Egypt, 4 de septiembre de 2013. [www. dailynewsegypt.com/2013/09/04/constitutional...mistakes/, consultado el 4 de septiembre de 2013.]

El-Sharnoubi, Osman, "How Your Daily Life may change under El-Sisi”, Al Ahram Online, 25 de julio de 2014. [english.ahram. org.eg/NewsContentPrint/1/0/107032/Egypt/0/How-your.. aspx, consultado el 25 de julio de 2014.]

ElshobaKi, Amr, "Realidad y futuro de la Revolución egipcia", Arraq, núm. 3, 2011, pp. 107-117.

Gardiner, Alan, The Admonitions of an Egyptian Sage from a Hieratic Papyrus in Leiden (Pap. Leiden 344 recto), Leipzig, J. C. Hinrichs'sche Buchhandlung, 1909.

Ghonim, Wael, Revolution 2.0. The Power of the People is Greater than the People in Power. A Memoir, Londres, Harper Collins, 2012.

Grecko, Témoris, "Egipto: el regreso de los generales", Proceso, núm. 1914, 6 de julio de 2013, pp. 54-56.

LANTIER, Alex, "Low Turnout as Egypt's US-Backed Junta Holds Constitutional Referendum", World Socialist Web Site, 16 de enero de 2014. [www.wsws.org/en/articles/2014/01/16egyp-j16. html, consultado el 16 de enero de 2014.]

LeILA, Reem, "Historic Ruling on Harassment", Al Abram Weekly, 24 de julio de 2014. [weekly.ahram.org/News/6864/17/Historic-. aspx, consultado el 24 de julio de 2014.]

MessiHa, Jean y Frédéric Teulon, "Egypte : de une révolution à une autre?”, Maghreb-Machrek, núm. 216, otoño de 2013, pp. 129-142.

NAssar, Galal, “The Battle over the Constitution”, Al Abram Weekly, 2 de enero de 2013. [weekly.ahram.org/Print/810.aspx, consultado el 29 de mayo de 2013.]

Nkrumah, Gamal, "Nasser and Now", Al Abram Weekly, 14 de febrero de 2011. [weekly.ahram.org/print/2011/1034/sc1102. htm, consultado el 14 de febrero de 2011.]

Rashwan, Nada Hussein, "Inside Egypt's Draft Constitution: Role of Sharia Redefined", Al Abram Online, 12 de diciembre de 2013. [english.ahram.org.eg/NewsContentPrint/1/0/88632/Egypt/0/ Inside-Egypts-...aspx, consultado el 12 de diciembre de 2013.]

RIzK, Mariam y Osman El Sharnoubi, “Egypt's Constitution 2013 vs. 2012: A Comparison", Al Ahram Online, 12 de diciembre de 2013. [english.ahram.org.eg/NewsContentPrint/1/0/88644/ 
Egypt/0/Egypts-constitution.aspx, consultado el 12 de diciembre de 2013.]

Shukrallah, Salma, "Egypt's Constitution: Who is backing It and Why?", Al Abram Online, 9 de enero de 2014. [english.ahram. org.eg/NewsContentPrint/1/0/90694/Egypt/0/Egypts-...aspx, consultado el 9 de enero de 2014.]

Stern, Johannes, "Egypt's New Constitution Legitimizes Coup, Enshrines Military Dictatorship”, World Socialist Web Site, 19 de diciembre de 2013. [www.wsws.org/en/articles/2013/12/19/ egypt-d19.html, consultado el 19 de diciembre de 2013.]

STERn, Johannes, "The Way forward in Egypt", World Socialist Web Site, 26 de noviembre de 2012. [www.wsws.org/tools/index. php?page = print, consultado el 26 de noviembre de 2012.]

STERN, Johannes, "Two Years of the Egyptian Revolution", World Socialist Web Site, 6 de febrero de 2013. [www.wsws.org/en/ articles/2013/01/25/perst-j25.html, consultado el 6 de febrero de 2013.]

TAREK, Sherif, "Inside Egypt's Draft Constitution: Debates over Military Powers Continue", Al Abram Online, 12 de diciembre de 2013. [english.ahram.org.eg/NewsContentPrint/1/0/88582/ Egypt/0/-Inside-Egypts-...aspx, consultado el 12 de diciembre de 2013.]

The Cairo Post, "2014 Constitution", 7 de diciembre de 2013. [thecairopost.com/news/50825/wiki/constitution, consultado el 7 de diciembre de 2013.]

The Constituent Assembly, The Nerw Constitution of the Arab Republic of Egypt. Approved on 30 November 2012, traducción extraoficial preparada por The International Institute for Democracy and Electoral Assistance. [www.constitutionnet.org/files/final_constitution_30 nov_2012_english-_-idea.pdf, consultado el 29 de mayo de 2013.] 